DOI: https://dx.doi.org/10.51145/jlsb.2021.4

\title{
Forbidden assisted reproduction method and the Islamic perspective
}

\author{
Aisha ALSHDEFAT ${ }^{1 \ltimes 凶}$ and Ehsan GHARIB MOMBENI ${ }^{2}$ \\ ${ }^{1} \mathrm{MSc}(\mathrm{N})$, Lecturer, Department of Maternal and Child Health, College of Nursing, Sultan Qaboos University, Alkhoud Muscat, Sultanate of Oman \\ ${ }^{2} \mathrm{PhD}$, Department of Pathobiology, Shahid Chamran University of Ahvaz, Iran \\ Corresponding author's Email: Alshdefat@squ.edu.Om; (D) ORCiD: 00oo-0002-6764-1043
}

\section{ABSTRACT}

Introduction. Assisted reproductive methods are used widely around the world to cure various kinds of infertility. These technologies had not been applied in the Islamic world for decades due to Islamic teachings do not approve these methods. However, nowadays, studying for infertility cure in Islam is allowed and promoted. Against the individual's thoughts that Islam laws are restricted on assisted reproductive cure, Islam ethics are liberal. Due to Islamic laws, all assisted reproductive technologies (ARTs) are acceptable, under the following conditions; the sperm, ovum, and uterus come from a legally married couple during their marriage period. Aim. In this survey, a brief editorial on surrogacy from an Islamic perspective is scrutinized.

\begin{tabular}{l} 
Short Communication \\
PII: S225199392100004-11 \\
\hline Rec. 22 January 2021 \\
Rev. 19 March 2021 \\
Acc. 25 March 2021 \\
\hline Keywords \\
Assisted reproduction \\
method, \\
Surrogacy, \\
Islamic perspective
\end{tabular}

\section{INTRODUCTION}

Infertility is a global health problem described as the inability after one year of frequent unprotected intercourse to achieve pregnancy [1]. It is believed, the impacts of infertility are as widespread as their incidence. The incidences consist of despair, anxiety, depression, decreased self-esteem, feelings of guilt, and frustration. Assisted reproductive methods are used widely around the world to cure various kinds of infertility. These technologies had not been applied in the Islamic world for decades due to Islamic teachings do not approved these methods.

However, nowadays, studying for infertility cure in Islam is allowed and promoted. Against the individual's thoughts that Islam laws are restricted on assisted reproductive cure, Islam ethics are liberal [2]. Treatments of infertility based on the following methods: genetic links, stigma, normative attitudes towards parents, and demographic attitude issues [3]. The use of assisted reproductive technologies has been associated with ethical, legal, and social controversies. One of the highly debatable assisted reproductive technologies is surrogacy [4].

Surrogacy or Surrogate is a pregnancy agreement that is assisted reproduction whereby a surrogate mother agrees to become pregnant to gestate and give birth to a child that will be raised by others parents [4]. Several reasons behind surrogate pregnancy, for example, a woman with a hysterectomy, uterine malformation, a history of recurrent abortion, or any medical disease making her pregnancy a risk to her health [3]. It is both the oldest and the most controversial of all assisted reproductive technologies $[4,5]$.

The Sultanate of Oman is an Arab-speaking country in the Middle East. Its official religion is Islam. 85.9 percent of their population estimated as Muslims. The rest population consists of Christianity (6.4\%), Hinduism (5.7\%), and Buddhism (0.8\%) [6]. In Oman, the male infertility rate ranged from 7-21 \%, while the female infertility rate ranged from 8-104\% (Annual health report, Ministry of Health, Oman, 2018; https://www.moh.gov.om/documents/).

According to the World Health Organization (WHO), about 1 in 4 couples in developing countries, 1 in 8 in industrialized countries, and about 8-12 percent of reproductive-age couples worldwide are affected by primary or secondary infertility [7]. Infertility in Middle Eastern countries is predicted to affect 10-15\% of married couples [8]. 
Infertility has a serious impact on the individual's psychology, emotions, and social interactions. Many studies defined infertility as a couple who not able to conceive or carry a baby to term [9]. Lindsay and Vitrikas [10] described that infertility is defined as the inability to become pregnant after one year of regular unprotected intercourse. The main causes of infertility are advanced maternal age, reproductive tract disorders, polycystic ovary syndrome, endometriosis, uterine fibroids, psychological stress, purposely delayed childbearing, environmental pollution, smoking, alcohol, and dietary habits [3].

For the majority of individuals, parenting is an integral part of life. Therefore, when couples are unable to have children, there may be numerous physical-, psychological-, and social-consequences. In recent years, there has been progressing in the therapies provided to infertile couples [11].

One of the main therapies is that most types of infertile couples are given called In Vitro fertilization (IVF). IVF is a hormonal process that makes the ovaries release several ova. At the proper time, these ova aspirated by a needle either through the vagina or abdomen surface. In the laboratory environment, these ova are fertilized by sperms. Thus, the zygotes (fertilized ova) after the fourth or eighth cellular growth stage are implanted in the uterus [3]. The process could not be against Islamic roles if the couples are legally married.

Surrogacy has two categories: traditional and gestational. In traditional surrogacy, the inseminated surrogate carrier is with the "commissioning couple" husband's semen, and the surrogate carrier will be the biological mother to the child she carried [12]. On the other hand, the gestational mother carries a child conceived with the intended mother's ovum and sperm from the intended father; the child will be biologic to the intended mother and intended father [12].

Furthermore, it was mentioned that Surrogacy considered an excellent option for the treatment of repetitious implantation failure [13]. Globally, attitude toward surrogacy as a method of assisted reproductive technology influencing different variables such as religion, gender, age, awareness of the procedure, and socioeconomic status [4].

Oman, as a Muslim country, follows the Islamic rule that encourages reproduction, supports the treatment of infertility, and protects the offspring includes treatment of pregnant women and child welfare. It further concerns that every newborn should understand the preservation of his parents' lineage. Both men and women shared the decision of reproductive is shared by, in the Middle East, the reproductive is a way to eternize the family offspring, as well as a forum for parents to get support and help with family labor, and both Muslim and Jewish middle eastern Muslim and Jewish men want children and want to parent [14].

Thus, surrogacy creates a problem of the identity and the concept of Islam to avoid mixing genes. Jordan is a Muslim Arab country that declares from their Council of the Islamic Fiqh academy that Surrogacy is prohibited in Islam and forbidden due to the consequences of lines misunderstanding and loss of parenting [15]. Islam supports the development of the family and assisted reproduction within the context of marriage, if indicated, within the context of marriage.

Moreover, the Islam considers the identification to mothers who give birth to their child as said in the holy

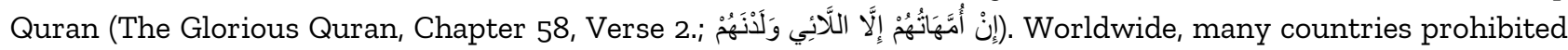
surrogacy, including China, France, Germany, Italy, Japan, Pakistan, Portugal, Saudi Arabia, Spain, and Turkey. Belgium, Canada, Denmark, Ireland, Israel, thus smaller numbers of countries, including Georgia, India, Mexico, Russia, Thailand, and Ukraine, allow for both commercial and altruistic surrogacies [16].

In Islam, all assisted reproductive technologies are allowed if the semen source, ovum source, an incubator (uterus) during the time of their marriage comes from the legally married husband and wife [5]. No third party should intrude upon the marital function of reproduction. According to Islam, the infertility of a man or woman should be, if it is beyond cure. Thus by replacing the embryos within the uterus of the second wife of the same husband who provided the spermatozoa, the Fatwa of the Islamic Fiqh Council of Makkah in 1984 authorized surrogacy, but the council revoked its surrogacy approval in 1985, And consider banning surrogacy under Islamic law [2].

\section{CONCLUSION}

It is highly unfortunate that millions of couples around the globe suffer from infertility issues and are reproductive challenged for various medical reasons. Genetic gestational surrogacy (husband's sperm and wife's ovum are fertilized and the embryos are transferred to the surrogate mother through IVF procedure) can 
be free from social, legal, and moral complications. Surrogacy has resulted in thousands of pregnancies being taken to term successfully and babies born to Intended Parents with help from surrogate mothers, allowing parenthood to those that have infertility over the world. Scientific publications on surrogacy pregnancy and its result in Oman are missing, and we expect this paper will contribute to increasing the awareness of surrogacy pregnancy in Oman under the Islamic perspective.

\section{DECLARATIONS}

\section{Authors' contributions}

Both the authors contributed equally to this work.

\section{Competing interests}

The authors declare that they have no competing interests.

\section{REFERENCES}

1. Sukanya, Reddamma GG, Harina Kumari PS A study to assess the knowledge and attitude regarding surrogacy among women attending selected infertility clinics at Bengaluru, with a view to developing an information guide sheet. World Journal of Pharmaceutical and Life Sciences WJPL; 2018; 4(12): 103-107. Article Link

2. Serour GI. Islamic perspectives in human reproduction. Reproductive biomedicine online. 2008; 17(sp3): 34-38. https://doi.org/10.1016/S1472-6483(10)60328-8

3. Al-Bar MA, Chamsi-Pasha H. Assisted reproductive technology: Islamic perspective. Contemporary bioethics, 2015 (pp. 173-186). Springer, Cham. https://doi.org/10.1007/978-3-319-18428-9 11

4. Mustafa AG, Alzoubi KH, Khabour OF, Alfaqih MA. Perspectives and attitudes of Jordanian medical and paramedical students toward surrogate pregnancy. International journal of women's health. 2018; 10: 617. PMCID: PMC6200074; https://dx.doi.org/10.2147\%2FIJWH.S184434

5. Fadel HE. The Islamic viewpoint on new assisted reproductive technologies. Fordham Urb. LJ. 2002; 30:147. Article link

6. Hackett C, Grim B, Stonawski M, Skirbekk V, Potančoková M, Abel G. The global religious landscape. Washington, DC: Pew Research Center. 2012 Dec 18. Google Scholar

7. Mascarenhas MN, Flaxman SR, Boerma T, Vanderpoel S, Stevens GA. Global prevalence of infertility, infecundity and childlessness. National, regional and global trends in prevalence since 1990: A systematic analysis of 277 Health surveys. World Health JP Med. 2012; 9(12):1-2. Google Scholar

8. Yazdi MS, Nasiri R, Jomei MG, Yazdi SS. Quality of life and general health in pregnant women conceived with assisted reproduction technologies: a case-control study. International Journal of Fertility \& Sterility. 2020; 13(4):271. PMCID: PMC6875863; https://dx.doi.org/10.22074\%2Fijfs.2020.5684

9. Dempsey D. Surrogacy, gay male couples and the significance of biogenetic paternity. New genetics and society. 2013; 32(1):37-53. https://doi.org/10.1080/14636778.2012.735859

10. Lindsay TJ, Vitrikas K. Evaluation and treatment of infertility. American family physician. 2015; 91(5): 308-314. Article link

11. Ramezanzadeh F, Noorbala AA, Abedinia N, Forooshani AR, Naghizadeh MM. Psychiatric intervention improved pregnancy rates in infertile couples. The Malaysian Journal of Medical Sciences: MJMS. 2011; 18(1):16. PMCID: $\underline{\mathrm{PMC} 3216204}$

12. Lones ME. A Christian ethical perspective on surrogacy. Bioethics in faith and practice. 2016; 2(1):5. Article Link

13. Aflatoonian N, Eftekhar M, Aflatoonian B, Rahmani E, Aflatoonian A. Surrogacy as a good option for treatment of repeated implantation failure: a case series. Iranian journal of reproductive medicine. 2013; 11(1):77. PMCID: PMC3941386

14. Inhorn MC, Birenbaum-Carmeli D, Tremayne S, Gürtin ZB. Assisted reproduction and Middle East kinship: a regional and religious comparison. Reproductive biomedicine \& society online. 2017; 4:41-51. https://doi.org/10.1016/j.rbms.2017.06.003

15. Islam S, Nordin RB, Ab Rani Bin Shamsuddin HB, Nor M, Al-Mahmood AK. Ethics of surrogacy: a comparative study of Western secular and Islamic bioethics. The Journal of IMA. 2012; 44(1). https://doi.org/10.5915/44-1-5920 ; PMCID: $\underline{\mathrm{PMC}} 3708631$

16. Chamie J, Mirkin B. Surrogacy: Human Rights or Reproductive Exploitation? Yale University. 2014. https://yaleglobal.yale.edu/content/surrogacy-human-right-or-reproductive-exploitation 